\title{
The geochemical behavior of dimethyl arsenate in a simulated wetland system
}

\author{
YOUNG-SOO HAN ${ }^{1}$, SO-JEONG KIM ${ }^{1}$, IN-HYUN NAM ${ }^{1}$, \\ AND JUNGHO RYU ${ }^{1}$ \\ ${ }^{1}$ Geologic Environment Division, Korea Institute of \\ Geoscience and Mineral Resources (KIGAM)
}

Arsenic (As) is one of the most problematic toxic pollutant caused by geogenic and anthropogenic sources. Among As species, methylated arsenic species were used as the main active ingredient in pesticides and herbicide and is often considered as the major source of incoming As pollutants in constructed wetlands. In the current study, geochemical reactions of dimethyl arsenate (DMAs) were investigated using a laboratory-simulated wetland microcosm experiments. The microcosms were set up with wetland water, sediment, and plants collected from a constructed wetland located in Chungbuk, Korea. The DMAs was injected in wetland water and the concentrations of As were monitored in wetland water, plant, and sediment. The liquid and solid phase As speciations were also determined using LC-ICP-MS and X-ray absorption spectroscopy for wetland water and solid samples, respectively. Experimental results revealed that the spiked DMAs was completely removed from wetland water and transported to wetland sediment and plants. Particularly, about $98-99 \%$ of As was adsorbed to wetland sediments as the form of inorganic $\mathrm{As}(\mathrm{V})$ or $\mathrm{As}(\mathrm{III})$. In wetland sediment, the amount of adsorbed As(III) was increased with sediment depth, demonstrating that demethylated $\mathrm{As}(\mathrm{V})$ was further reduced to $\mathrm{As}(\mathrm{III})$ when redox condition changed in the sediment layer. The As reduction observed in the sediment layer could cause release of As to aqueous system again and caution should be taken in wetland management to prevent secondary release of As. 